\title{
Nitric oxide triggers apoptosis in A375 human melanoma cells treated with capsaicin and resveratrol
}

\author{
MIN YOUNG KIM \\ Faculty of Biotechnology, College of Applied Life Sciences, Jeju National University, Jeju 690-756, Republic of Korea
}

Received June 26, 2011; Accepted September 20, 2011

DOI: $10.3892 / \mathrm{mmr} .2011 .688$

\begin{abstract}
Capsaicin and resveratrol are strong chemopreventive agents with promising human consumption safety records and anticarcinogenic activities. However, the mechanism by which they induce apoptosis in tumor cells remains to be defined. In this study, we examined the role of nitric oxide (NO*) during apoptosis induced by these agents in A375 human melanoma cells. Capsaicin and resveratrol, alone or in combination, inhibited cell growth and promoted apoptosis by the elevation of $\mathrm{NO}^{*}$ in A375 cells. Increased $\mathrm{NO}^{\circ}$ production following treatment stimulated p53 and triggered mitochondrial apoptotic events by inducing conformational changes in Bax and Bcl-2 with subsequent release of cytochrome $\mathrm{c}$ and activation of caspase 9 and 3. Caspase 8 activation concurrently appeared to be mediated by death receptor processing and downstream caspases. Collectively, our data suggest that capsaicin and resveratrol activate the mitochondrial and death receptor pathways, working together to induce apoptosis in A375 cells, and indicate that $\mathrm{NO}^{\circ}$ could be considered a potential target for improvement of the effectiveness of melanoma treatment.
\end{abstract}

\section{Introduction}

Melanoma, a solid tumor that arises from pigment-producing melanocytes, is the most aggressive and lethal type of cutaneous cancer and is notoriously resistant to all current modalities of cancer therapy $(1,2)$. Melanoma represents only $4 \%$ of all skin cancers, but almost $80 \%$ of skin cancer mortality $(1,3,4)$. Alternative options for patients with malignancies include natural compound treatments that have been used for a number of years throughout the world (5-9). Among natural

Correspondence to: Dr Min Young Kim, Faculty of Biotechnology, College of Applied Life Sciences, Jeju National University, Ara-1 dong, Jeju 690-756, Republic of Korea

E-mail: jeffmkim@jejunu.ac.kr

Abbreviations: $\mathrm{NO}^{\circ}$, nitric oxide; NOS, nitric oxide synthase; iNOS, inducible NOS; eNOS, endothelial NOS; nNOS, neuronal NOS; DMSO, dimethyl sulfoxide; $\mathrm{NO}_{3}^{-}$, nitrate; $\mathrm{NO}_{2}^{-}$, nitrite; PMSF, phenylmethylsulfonyl fluoride; PVDF, polyvinylidene difluoride

Key words: nitric oxide, capsaicin, resveratrol, A375 cells compounds, capsaicin ( $N$-vanilly-8-methyl-1-nonenamide) and resveratrol (trans-3,5,4'-trihydroxystilbene) have experienced increasing attention from the scientific and medical field due to their substantial antimutagenic and anticarcinogenic potentials $(6,10-12)$. However, the molecular mechanism by which they selectively induce apoptosis in cancer cells has not yet been fully elucidated.

Nitric oxide (NO*), a product synthesized endogenously via arginine metabolism by various isoforms of nitric oxide synthase (NOS), is a pleiotropic signaling molecule that facilitates a wide variety of basic cellular functions and manifests itself pathophysiologically (13). The effects of capsaicin-induced $\mathrm{NO}^{\circ}$ production have been reported in rat pheochromocytoma, PC-12 (14) and C6 glioma (15) cells. Some in vitro studies have shown that resveratrol is capable of inducing apoptosis through the elevation of $\mathrm{NO}^{\bullet}$ concentration in the human breast cancer cell line MCF-7 (16) and exerts antiproliferative action on HepG2 hepatocellular carcinoma cells by NOS activation (17).

Based on the collective evidence that capsaicin and resveratrol share the ability to stimulate $\mathrm{NO}^{*}$ production in certain cell types, we hypothesized that they may act synergistically in the induction of apoptosis via this pathway. To test this hypothesis, we examined mechanisms of death signaling induced by capsaicin and resveratrol with special emphasis on the role of $\mathrm{NO}^{\circ}$, employing A375 human melanoma cells. We selected this cell line as existing evidence suggests the possible involvement of $\mathrm{NO}^{*}$ in the etiology of melanoma (18).

\section{Materials and methods}

Cell cultures and chemicals. The melanoma cell line, A375, kindly provided by Dr G.N. Wogan (Massachusetts Institute of Technology, USA) was cultured in high glucose Dulbecco's modified Eagle's medium (DMEM) containing 10\% heat-inactivated fetal bovine serum, $100 \mathrm{units} / \mathrm{ml}$ penicillin, $100 \mu \mathrm{g} / \mathrm{ml}$ streptomycin and $2 \mathrm{mM} \mathrm{L-glutamine} \mathrm{under} 5 \% \mathrm{CO}_{2}$ at $37^{\circ} \mathrm{C}$.

All cell culture reagents were purchased from Lonza (Walkersville, MD, USA). Capsaicin, resveratrol, Ac-DEVD-CHO and a GenElute ${ }^{\mathrm{TM}}$ mammalian genomic DNA miniprep kit were purchased from Sigma (St. Louis, MO, USA), and N-methyl-L-arginine monoacetate (NMA) was from CalBiochem (Salt Lake City, UT, USA). A total NO quantitative detection kit was purchased from R\&D Systems (Minneapolis, MN, USA); the Annexin V-FITC apoptotic 
assay kit was from Clontech Laboratories (Palo Alto, CA, USA); Mitochndria/Cytosol Fractionation kit was purchased from Biovision (Mountain View, CA, USA); the ECL ${ }^{\mathrm{TM}}$ Western blotting detection reagents was from GE Healthcare Bio-Sciences (Piscataway, NJ, USA); and the ApoAlert Caspase-3 Colorimetric Assay kit was from Clontech (Mountain View, CA, USA). RIPA lysis buffer, anti-NOS1 (neuronal NOS, nNOS), anti-NOS2 (iNOS), anti-NOS-3 (endothelial NOS, eNOS), and anti-bcl-2 antibodies, as well as secondary goat anti-rabbit or anti-mouse IgG conjugated to horseradish peroxidase were obtained from Santa Cruz Biotechnology (Santa Cruz, CA, USA); anti-Bax, anti-caspase 8 and 3 antibodies were from Cell Signaling Technology (Beverly, MA, USA); anti-DR4 and anti-Fas antibodies were from StressGen Biotechnologies Corp (Victoria, BC, Canada); anti-caspase 9, anti-Mdm2 and anti-cytochrome c antibodies were from BD Pharmingen (San Diego, CA, USA); and anti-p53 and anti-actin antibodies were provided by Oncogene (Cambridge, MA, USA).

Growth and cell viability analysis. A375 cells were placed in 24-well plates at a density of $1 \times 10^{5}$ cells/well. Different concentrations of capsaicin or resveratrol were then added to the cells for final concentrations of 10,25, 50, 100 and $200 \mu \mathrm{M}$ for $24 \mathrm{~h}$, or $100 \mu \mathrm{M}$ capsaicin and/or $50 \mu \mathrm{M}$ resveratrol for different periods of time, and dimethyl sulfoxide (DMSO; solvent) only for the control regimen, and grown at $37^{\circ} \mathrm{C}$, in $5 \% \mathrm{CO}_{2}$. Adherent and non-adherent cells were pooled after the 24-h treatment and a small sample of each cell suspension was diluted 1:1 in trypan blue and counted under a light microscope. The effects of the treatment were quantified as the percentage of cell survival using DMSO as the control.

Determination of $\mathrm{NO}^{\bullet}$ level. Following each period of exposure time, total $\mathrm{NO}^{-}\left[\right.$nitrate $\left(\mathrm{NO}_{3}^{-}\right)+$nitrite $\left(\mathrm{NO}_{2}^{-}\right)$] production in cell culture supernatants was measured with a total NO quantitative kit. Briefly, $50 \mu \mathrm{l}$ of culture supernatant was allowed to react with $100 \mu \mathrm{l}$ of Griess reagent and incubated at room temperature for 10-30 min. For measurement of total $\mathrm{NO}{ }^{\bullet}$ production, $\mathrm{NADH}$ and $\mathrm{NO}_{3}{ }^{-}$reductase were added prior to the reaction with the Griess reagent. Optical density was measured using a microplate reader at $540 \mathrm{~nm}$. Fresh culture media served as the blank in all experiments. Total $\mathrm{NO}^{\circ}$ concentrations were calculated from standard curves derived from $\mathrm{NO}_{3}{ }^{-}$standard solution provided with the kit. The values are expressed in pmoles $/ 10^{6}$ viable cells/sec.

Apoptosis analysis. Cells $\left(3 \times 10^{6}\right)$ in a $60-\mathrm{mm}$ tissue culture dish with $100 \mu \mathrm{M}$ of capsaicin and/or $50 \mu \mathrm{M}$ of resveratrol were incubated for $48 \mathrm{~h}$. Cells were harvested by trypsinization, centrifugation and measured by a Becton-Dickinson FACScan (excitation at $488 \mathrm{~nm}$ ) equipped with CellQuest software following Annexin V-FITC and propidium iodide staining, which was performed by modification of a previously described (19) protocol. Apoptotic cells were labeled with Annexin V (early apoptosis) or with Annexin V and propidium iodide (late apoptosis); necrotic cells were stained with propidium iodide and living cells were negative for the two stains. Cells treated with DMSO and $50 \mu \mathrm{M}$ etoposide were used as a negative and positive control, respectively.
DNA fragmentation. For analysis of DNA fragmentation by agarose gel electrophoresis, total DNA was isolated from cells treated with $100 \mu \mathrm{M}$ of capsaicin and/or $50 \mu \mathrm{M}$ of resveratrol for $48 \mathrm{~h}$ using a GenElute ${ }^{\mathrm{TM}}$ mammalian genomic DNA miniprep kit. The isolated DNA was suspended in TE buffer (10 mM Tris-HCl, 1 mM EDTA, pH 9.0) and quantified by absorbance at $260 \mathrm{~nm}$. Fragmented DNA was loaded onto $1.8 \%$ agarose gel containing $1 \mathrm{X}$ TBE buffer and separated by electrophoresis for $2 \mathrm{~h}$ at $50 \mathrm{~V}$, and images were captured following staining with $0.5 \mathrm{ng} / \mathrm{ml}$ ethidium bromide.

Whole cell extract and mitochondria-free cytosolic fraction preparation. Cells were harvested following treatment for $48 \mathrm{~h}$ and were lysed in $450 \mu \mathrm{l}$ of ice-cold RIPA lysis buffer [1X TBS, $1 \%$ Nonidet P-40, $0.5 \%$ sodium deoxycholate, $0.1 \%$ SDS, $0.004 \%$ sodium azide, $1 \mathrm{mM}$ phenylmethylsufonyl fluoride (PMSF), sodium orthovanadate supplemented with $20 \mu \mathrm{g} /$ $\mathrm{ml}$ protease inhibitor cocktail; Santa Cruz Biotechnology] for 30-60 min on ice, centrifuged at $10,000 \mathrm{x} \mathrm{g}$ for $10 \mathrm{~min}$ at $4^{\circ} \mathrm{C}$, and the protein concentration in the resulting supernatant was measured by the Bradford method (Bio-Rad, Hercules, CA, USA) prior to Western blot analysis.

Cytosolic fractions from control and treated cells were prepared using a kit from BioVision. Briefly, cells $\left(3 \times 10^{6}\right)$ were treated with $100 \mu \mathrm{M}$ of capsaicin and/or $50 \mu \mathrm{M}$ of resveratrol for $48 \mathrm{~h}$. The cells were collected, pelleted by centrifugation and washed with ice-cold phosphate-buffered saline (PBS). The cells were suspended in cytosol extraction buffer supplied by the manufacturer and incubated on ice for $10 \mathrm{~min}$. The cells were then homogenized using an ice-cold dounce tissue grinder, and the homogenate was centrifuged at 10,000 x g for $30 \mathrm{~min}$ to separate cytosol and mitochondria. The supernatant, including the cytosolic fraction, was collected and frozen at $-80^{\circ} \mathrm{C}$ for cytochrome $\mathrm{c}$ analysis.

Western blot analysis. Approximately $60 \mu \mathrm{g}$ of protein from the whole-cell lysate or the cytosolic fractions was denatured, separated by $15 \%$ (or $7.5 \%$ for NOS isoforms) SDS-PAGE gel electrophoresis and blotted onto a polyvinylidene difluoride (PVDF) membrane (Bio-Rad), which was then blocked with $5-7 \%(w / v)$ non-fat dry milk in Tris-buffered saline/0.1\% Tween-20 (TBS/T, pH 7.6) for 1-3 h at room temperature. The membranes were incubated at $4{ }^{\circ} \mathrm{C}$ overnight with either anti-NOS1 (diluted 1:500), anti-NOS2 (1:500), anti-NOS-3 (1:1000), anti-p53 (1:1000), anti-Mdm2 (1:1000), anti-Bax (1:1000), anti-bcl-2 (1:1000), anti-DR4 (1:1000), anti-Fas(CD95) (1:2000), anti-caspase 8 (1:1000), anti-caspase 9 (1:1000), anti-cytochrome c (1:2000), anti-caspase 3 (1:1000), or anti-actin (1:8000). After being washed twice for $10 \mathrm{~min}$ with TBS/T, blots were incubated with the corresponding peroxidase-conjugated secondary goat anti-rabbit or mouse IgG (diluted 1:8000) for $1 \mathrm{~h}$ at room temperature, followed by washing 2 times for $5 \mathrm{~min}$ and 4 times for $10 \mathrm{~min}$, and detection of enhanced chemiluminescence by exposure to Hyperfilm ECL.

Caspase 3 activity assay. The caspase 3 activity of treated cells was determined using an ApoAlert Caspase-3 Colorimetric Assay kit. Cells $\left(2 \times 10^{6}\right)$ were counted and centrifuged at $400 \mathrm{x} \mathrm{g}$ for $5 \mathrm{~min}$, resuspended in $50 \mathrm{ml}$ of chilled cell lysis buffer, and then incubated on ice for $10 \mathrm{~min}$. Cell lysates were 
A

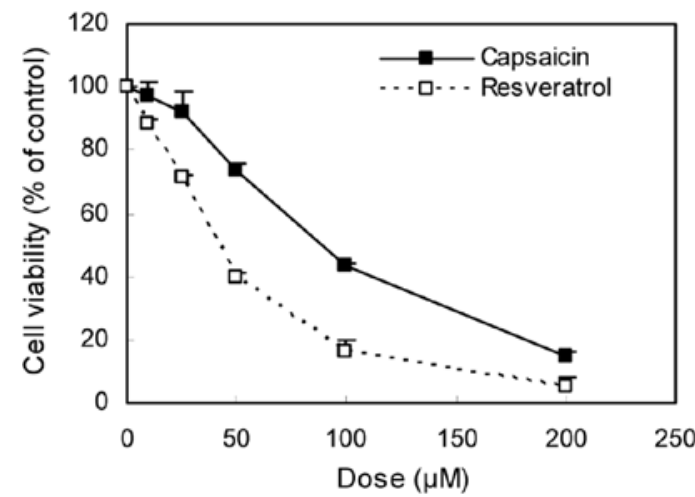

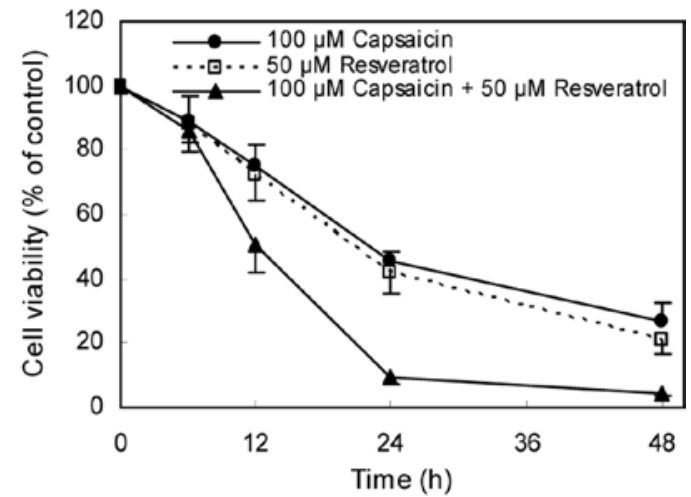

Figure 1. The percentage of viable A375 cells following capsaicin and/or resveratrol treatment. Cells were treated with the indicated concentrations (A) for $24 \mathrm{~h}$, or $100 \mu \mathrm{M}$ of capsaicin and/or $50 \mu \mathrm{M}$ of resveratrol (B) for 6, 12, 24 and $48 \mathrm{~h}$. Each point is the mean \pm SD of three experiments.

centrifuged at $16,000 \mathrm{x}$ g for $10 \mathrm{~min}$ at $4^{\circ} \mathrm{C}$ to precipitate cellular debris. A total amount of $50 \mu \mathrm{l}$ of $2 \mathrm{X}$ reaction buffer/DTT mix and $50 \mu \mathrm{M}$ of caspase 3 substrate DEVD-pNA were added to each transferred supernatant. The samples were incubated at $37^{\circ} \mathrm{C}$ for $1-3 \mathrm{~h}$ in a water bath, and read at $405 \mathrm{~nm}$ using a $\mu \mathrm{Quant}$ plate reader from Biotek Instruments Inc. (Winooski, VT, USA).

Statistical analysis. The two-tailed Student's t-test was used to analyze the statistical analysis between the capsaicin- and/or resveratrol-treated and control groups.

\section{Results}

Effect of capsaicin and/or resveratrol on cell viability. Cells were treated with $0,10,25,50,100$ and $200 \mu \mathrm{M}$ of capsaicin or resveratrol for $24 \mathrm{~h}$. Capsaicin and resveratrol decreased the percentage of viable cells dose-dependently (Fig. 1A). Following exposure to $100 \mu \mathrm{M}$ capsaicin and $50 \mu \mathrm{M}$ resveratrol for 24 h, viability was 43 and 40\%, respectively (Fig. 1A).

We next assessed the time course of viability using these doses of the two compounds, alone or in combination, and the percentage of viable cells was decreased in a time-dependent manner; the highest cytotoxic effect was observed when used in combination $(100 \mu \mathrm{M}$ capsaicin $+50 \mu \mathrm{M}$ resveratrol $)$ (Fig. 1B).

Expression of NOS isoenzyme protein and total NO ${ }^{\bullet}$ production. Western blot analysis showed the expression of 3 NOS isoforms in A375 cells treated with capsaicin and/or resveratrol (Fig. 2A). Resveratrol alone or in combination with capsaicin produced major differences in nNOS and iNOS.

Rates of total $\mathrm{NO}^{*}$ production were calculated from concentrations of $\mathrm{NO}_{3}^{-}$plus $\mathrm{NO}_{2}^{-}$in culture media following treatment for 6-48 h. As summarized in Fig. 2B, time-dependent increases in rates of total $\mathrm{NO}^{\circ}$ production were observed in cells in response to all treatments. Cells treated with either capsaicin or resveratrol alone for $48 \mathrm{~h}$ showed 2 - to 40 -fold increases in the $\mathrm{NO}^{\circ}$ production rate, as compared with controls, and the increases were further enhanced by combination treatment.

Effect of NMA on capsaicin and/or resveratrol induced cell growth inhibition. As shown in Fig. 2A and B, capsaicin and/
A

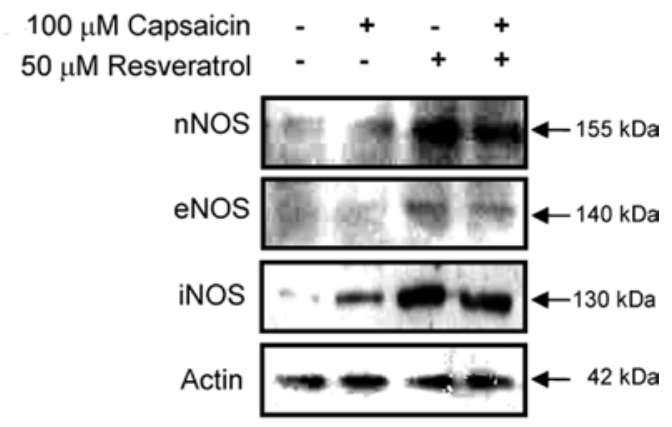

B

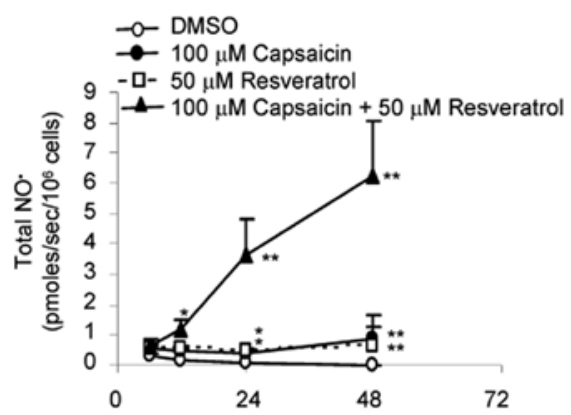

C

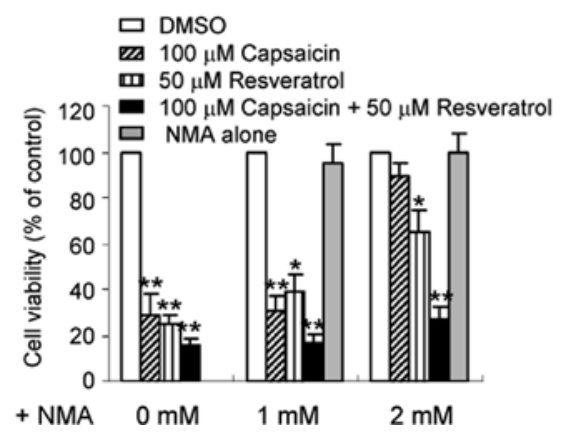

Figure 2. Effect of capsaicin and/or resveratrol on the expression of (A) NOS isoforms, (B) total NO' production and (C) effect of NMA on cell growth in A 375 cells. Results are shown as the mean $\pm \mathrm{SD}(\mathrm{n}=3)$. ${ }^{*} \mathrm{p}<0.05$ and ${ }^{* *} \mathrm{p}<0.01$, as compared with the DMSO control.

or resveratrol was a potent $\mathrm{NO}^{\bullet}$ inducer. In order to investigate whether $\mathrm{NO}^{\bullet}$ production interfered with cell growth, we incubated melanoma cells with 1 and $2 \mathrm{mM}$ of NMA, an NOS inhibitor. When cells were incubated with capsaicin and/or resveratrol and increasing concentrations of NMA, 
A
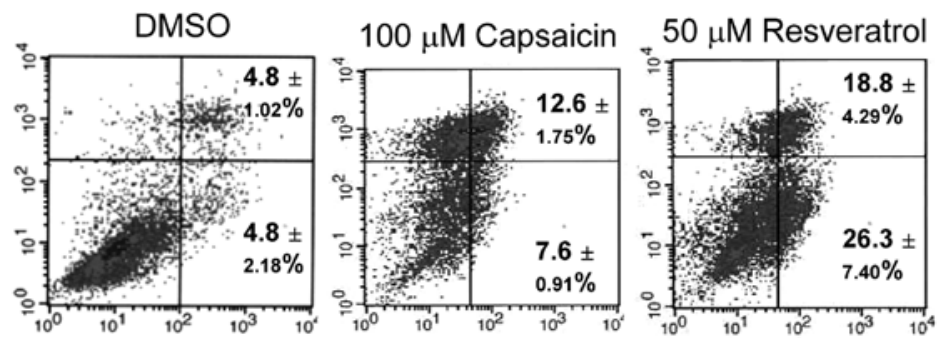

$100 \mu \mathrm{M}$ Capsaicin

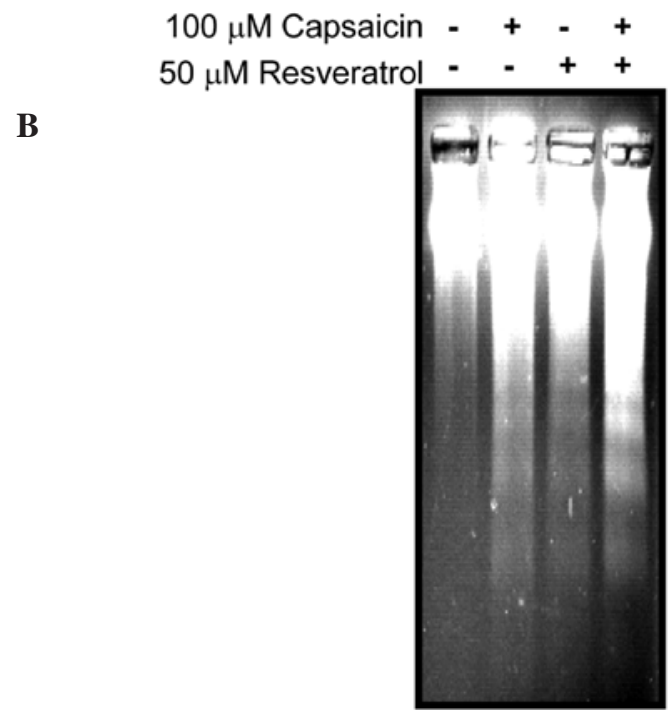

$+50 \mu \mathrm{M}$ Resveratrol
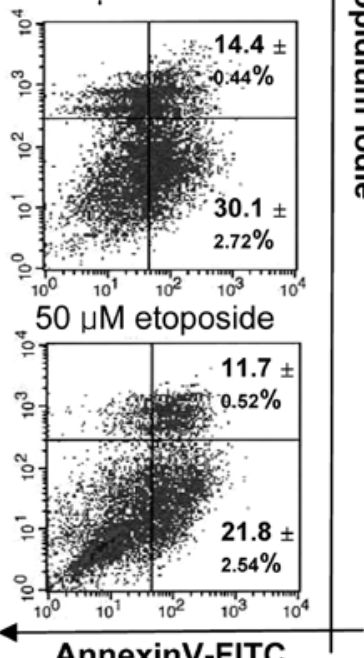

Figure 3. Induction of apoptosis by capsaicin and/or resveratrol. (A) Apoptosis was determined by Annexin V vs. PI staining. (B) Internucleosomal DNA fragmentation of A375 cells.

a dose-dependent attenuation of the antiproliferative effect of capsaicin and/or resveratrol was observed (Fig. 2C). Our results indicate that the enhanced $\mathrm{NO}^{\circ}$ production is a prerequisite for cell growth inhibition induced by capsaicin and/or resveratrol.

Apoptosis of A375 cells identified by flow cytometric analysis. Fig. 3A shows that capsaicin and/or resveratrol induced apoptosis in A375 cells. Approximately $20 \%$ of cells were apoptotic following capsaicin treatment and $45 \%$ following resveratrol treatment in A375 cells (2.1- and 4.7-fold over control level); combined treatment was more effective compared to either capsaicin or resveratrol alone (Fig. 3A).

Internucleosomal DNA fragmentation. One of the biochemical features of apoptosis is the fragmentation of genomic DNA; therefore, we isolated the genomic DNA after treating the cells for $48 \mathrm{~h}$ with capsaicin and/or resveratrol. The two compounds induced a DNA ladder formation; combined treatment was more effective than either capsaicin or resveratrol alone. Laddering confirmed death by apoptosis of the melanoma cells treated with these compounds (Fig. 3B).

Expression of intrinsic apoptotic pathway-regulating proteins p53, Mdm2, Bax and Bcl-2. As a next step, we investigated the mechanisms underlying capsaicin- and resveratrol-induced cell death with a focus upon apoptosis-regulating proteins. For this purpose, we first examined the expression of p53, Mdm2, Bax and Bcl-2 proteins. Treatment of the cells with capsaicin and/or resveratrol for $48 \mathrm{~h}$ led to a substantial elevation in cellular p53 levels accompanied by decrease in Mdm2 levels in A375 cells (Fig. 4A). The highest p53 and lowest Mdm2 levels were observed in the combination treatment, showing that capsaicin plus resveratrol accelerated the release of $\mathrm{p} 53$ by $\mathrm{Mdm} 2$ and its accumulation in the nuclei. The Bax gene, a proapoptotic member of the Bcl-2 family, is a significant target for p53. Our results from the Western blot analysis showed a slight elevation in Bax protein level and a pronounced down-regulation in Bcl-2 upon capsaicin and/or resveratrol treatment (Fig. 4A).

Expression of extrinsic apoptotic pathway-regulating proteins DR4, Fas and caspase 8. Next, we considered whether the extrinsic pathway was involved in the death of treated A375 melanoma cells. We analyzed the activation of DR4, Fas and caspase 8 in these treated and untreated cell lines. Western blot analysis reported in Fig. 4B shows an increase in DR4 and Fas (CD95), though a decrease in procaspase 8 protein level after capsaicin and/or resveratrol. When cells were treated with combined treatment, the level of their activation was maximum or minimum similar to other apoptosis regulatory proteins (Fig. 4B). An increased protein degradation of the cleaved form of caspase 8 in the capsaicin and/or resveratrol treated melanoma could explain the lack of this active form ( 43 and $18 \mathrm{kDa}$ ) in the Western blot analysis. These findings suggested that the intrinsic and extrinsic apoptotic pathways are involved in the death of the treated melanoma cells. 


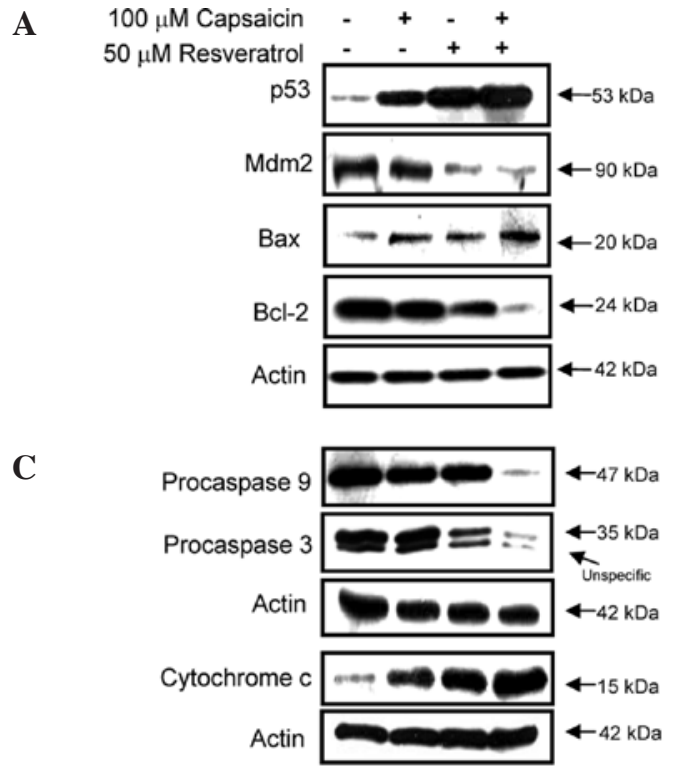

B
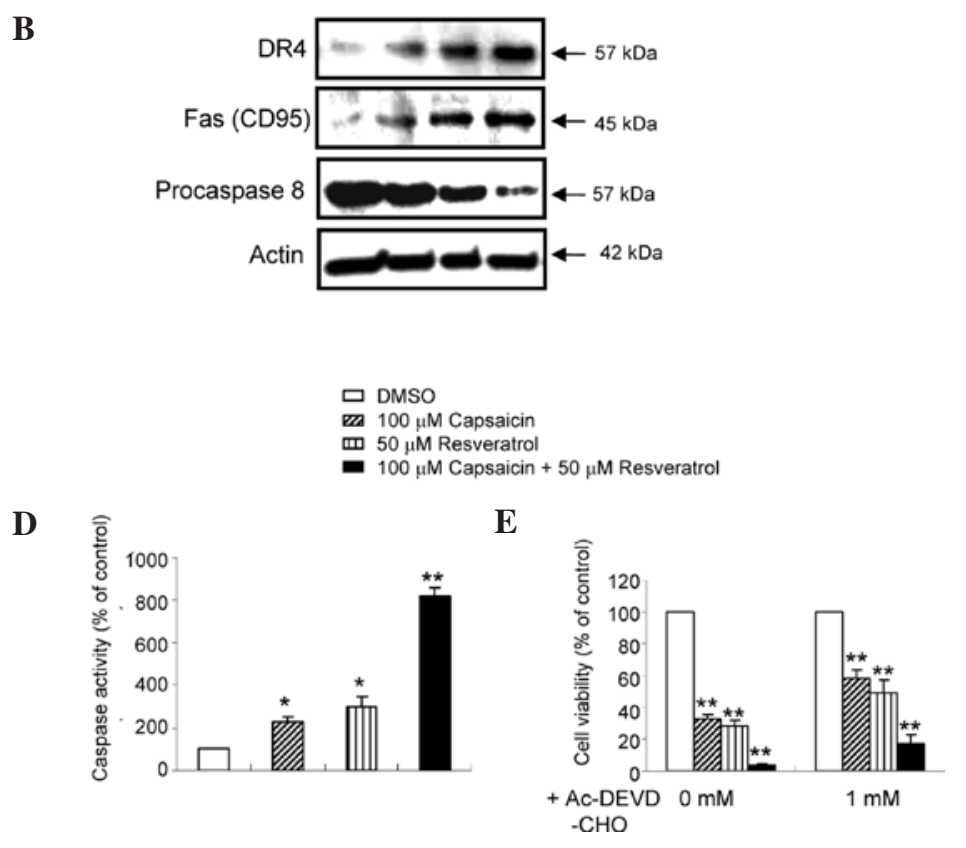

Figure 4. Representative Western blotting showing changes in the levels of (A) p53, Mdm2, Bax and Bcl-2; (B) DR4, Fas and caspase 8, and (C) participation of caspases in apoptosis. Results are representative of two independent experiments. (D) Caspase 3 activity (mean \pm SE, $n=3$ ), and (E) cell growth by pre-incubation with caspase inhibitor, Ac-DEVD-CHO, for $1 \mathrm{~h}$ prior to treatment (mean $\pm \mathrm{SD}, \mathrm{n}=3$ ). ${ }^{*} \mathrm{p}<0.05$ and ${ }^{* *} \mathrm{p}<0.01$, as compared with the control.

Caspase-dependent cascade (caspase 9, cytochrome $c$ and caspase 3). It is well known that a variety of stress stimuli lead to activation of caspases; therefore, we examined by Western blotting whether the apoptotic death induced by capsaicin and/ or resveratrol was caspase-dependent. We found a decrease in the precursor form of caspase 9 and cytochrome c release in the capsaicin- and/or resveratrol-treated cells (Fig. 4C). Accordingly, data from the Western blot analysis showed that degradation of procaspase 3 is accompanied by a significant increase in caspase 3 activity in the colorimetric assay based on the cleavage of the synthetic peptide Ac-DEVD-pNA (Fig. 4D). To investigate whether caspase 3 activity is critical for the capsaicin- and resveratrol-induced growth inhibition, we pretreated these cells with caspase 3 inhibitor, Ac-DEVD-CHO. As shown in Fig. 4E, Ac-DEVD-CHO attenuated capsaicin and/or resveratrol-induced growth inhibition, indicating that caspase 3 activity may be involved in the induction of growth inhibition by these agents.

\section{Discussion}

The aim of this study was to dissect the biochemical and molecular events associated with programmed cell death in melanoma following treatment with capsaicin and resveratrol. Although the anticancer function of capsaicin and resveratrol remains controversial, our results have clearly demonstrated that capsaicin and resveratrol inhibit cell growth (Fig. 1) and promote apoptosis (Fig. 3) in the cell line A375. Data presented here of increased $\mathrm{NO}^{\circ}$ production with capsaicin and resveratrol treatment and the activation of NOS levels (Fig. 2), suggest that $\mathrm{NO}^{\bullet}$ regulation accounts for the mechanism of capsaicin and resveratrol's action in this cell line.

The specific role of $\mathrm{NO}^{*}$ in tumor biology and cancer remains elusive; the generation of $\mathrm{NO}^{*}$ by tumor cells may inhibit activation and proliferation or increase apoptosis of surrounding lymphocytes that could account for the immune suppression observed that accompanies tumor growth, whereas, high intratumoral output of $\mathrm{NO}^{*}$ could inhibit the activation of caspases and, therefore, antagonize the pro-apoptotic signal $(20,21)$. However, the opposite effect also has been observed in numerous other systems whereby the generation of high output of $\mathrm{NO}^{\circ}$, either iNOS inducted or by the use of $\mathrm{NO}^{\circ}$ donors, inhibits tumor growth and metastasis $(21,22)$. The final outcome of $\mathrm{NO}^{-}$-mediated effects is variable, depending on a number of factors including cell type, $\mathrm{NO}^{\bullet}$ concentration, exposure duration, sources of $\mathrm{NO}^{\circ}$ and intracellular redox status.

Significantly, in this present study, we demonstrated that capsaicin and resveratrol cause an up-regulation of NOS activity and, in turn, produce an increase in $\mathrm{NO}^{\circ}$, leading to cell death in A375 cells (Figs. 1 and 2). In addition, we showed that a combined treatment induced the strongest response compared with either capsaicin or resveratrol alone (Fig. 2A and B). Moreover, using NMA, a NOS inhibitor, cell growth returned to normal levels (Fig. 2C), confirming that capsaicin- and resveratrol-induced $\mathrm{NO}^{\circ}$ production contributes to the overall fate of A375 cells. DNA fragmentation suggested that capsaicin- and/or resveratrol-induced cell death involved a mechanism of apoptosis, and this hypothesis was confirmed by flow cytometric analysis (Fig. 3). In fact, approximately half of the A375 cells became permeable to PI and Annexin V after $48 \mathrm{~h}$ with the combination treatment (Fig. 3A). A dual role of capsaicin and resveratrol in modulating $\mathrm{NO}^{*}$ production has been reported. A number of investigators have found that these compounds suppress $\mathrm{NO}^{\bullet}$ production, whereas others have observed enhancement of NO ${ }^{\bullet}$ production. Capsaicin (23-25) and resveratrol (26) inhibited IFN- $\gamma$ and LPS-mediated NO* production and iNOS protein expression in RAW264.7 macrophages, and resveratrol reduced $\mathrm{NO}^{\bullet}$ production in leukemic 
cells (27). The data that we present here indicate a direct relationship between increased NO ${ }^{\bullet}$ production and programmed tumor cell death (Figs. 1-3) by treatment with resveratrol and capsaicin. These data are supported by previous reports that capsaicin promotes iNOS expression and $\mathrm{NO}^{\bullet}$ production and leads to inhibition of proliferation in PC-12 (14) and C6 glioma (15) cells. Furthermore, the literature indicates that resveratrol increases $\mathrm{NO}^{*}$ production and induction of apoptosis in MCF-7 human breast cancer (16), HepG2 hepatocellular carcinoma (17) and gastric adenocarcinoma (28) cells.

Mammalian cells have two major apoptotic pathways, the intrinsic and extrinsic, which converge on the activation of the initiator and of the effector caspases $(13,21,29)$. The intrinsic pathway is dependent on the release of mitochondrial cytochrome $\mathrm{c}$ and other pro-apoptotic molecules into the cytoplasm. The association of cytochrome $\mathrm{c}$ with an adapter molecule, Apaf1, which activates caspase 9 in the cytoplasm, which, in turn, activates downstream caspases $(13,21,29)$ has been noted. Expression of wild-type p53 released by Mdm2 increases the sensitivity of cells to apoptosis and regulates Bcl-2 family proteins which modulate the mitochondrial pathway of apoptosis $(13,21,29)$. In the extrinsic pathway, the binding of specific death ligands to their respective cell surface receptors, such as Fas (CD95), tumor necrosis factor (TNF) receptor (TNFR), and the TNF-related apoptosis-inducing ligand (TRAIL) receptors DR4 and DR5, activate downstream pathways through the recruitment of an initiator (caspase 8), which, in turn, cleaves further effector caspases $(13,21)$. Thus, in order to understand the p53-related mechanisms used by capsaicin and resveratrol to activate the apoptotic pathway, we first analyzed the expression of p53, Mdm2 and the Bcl-2 family utilizing A375 cells (Fig. 4A). Capsaicin and/or resveratrol exposure stimulated p53 as well as Bax expression, while the p53 regulator gene Mdm2 was distinctly inhibited in A375 cells. Reduction of the anti-apoptotic p53-downstream target Bcl-2 expression was consequently detectable in A375 cells, suggesting that reduced levels of anti-apoptotic Bcl-2 protein, which are p53- and Bax-independent, play a role in cytochrome c release and apoptosis induced by capsaicin and resveratrol (Fig. 4A). Our results agree with previous findings that capsaicin and resveratrol modulate the processes of apoptosis in tumor cells through caspase activation accelerated by the decreased level of Bcl-2 (15,30,31). We also found the activation of caspase 9 together with caspase 3 , indicating that these compounds induce apoptosis via the mitochondrial pathway. Up-regulation of DR4 and Fas (CD95) and activation of caspase 8 (Fig. 4B) suggest that these compounds activate both the mitochondrial and death receptor pathways and work together to induce apoptosis (Fig. 4A and B). Although the mitochondrial and death receptor pathways are distinct, there is considerable crosstalk between them $(13,21)$. For example, activated caspase 8 in response to TNF- $\alpha$ can cleave Bid, a Bcl-2 family member, thereby converting Bid to a pro-apoptotic molecule that could promote cytochrome c release (21). In this study, we found that capsaicin and/or resveratrol induce the release of cytochrome $\mathrm{c}$ into the cytosol, confirming the existence of the two apoptotic pathways (Fig. 4C).

Caspases play an essential role in the apoptotic signal cascade. Caspases 8 and 9 are initiator caspases capable of transducing apoptotic signals by directly activating the down- stream executioner caspase $3(13,21,29)$. A number of studies have shown that $\mathrm{NO}^{\bullet}$ induces caspase-dependent apoptosis via both mitochondrial and death receptor pathways (13), and this prompted us to investigate whether $\mathrm{NO}^{\circ}$ is a target molecule in capsaicin- and resveratrol-induced apoptosis. We report, here, that these compounds promoted the activity of caspase 3 by colorimetric assay (Fig. 4D). We also showed that the addition of caspase 3 inhibitor, Ac-DEVD-CHO, inhibited caspase 3 activity and led to growth in these cells (Fig. 4E). These results demonstrate that capsaicin- and resveratrol-induced apoptosis might involve $\mathrm{NO}^{\circ}$ - and a caspase 3 -mediated mechanism.

Capsaicin and resveratrol have been reported to induce apoptosis through the multiple and contradictory death signaling events; caspase activation dependent $(16,32)$ and independent (33) of cytochrome c release, p53 and/or Bax-dependent (34) and -independent (35) cell death and death receptor dependent death signaling (36). For instance, the decrease in Bcl-2 levels is associated with cytochrome $\mathrm{c}$ release from the mitochondria and caspase-mediated apoptosis in numerous cases, while, in MCF-7 cells, even at high concentrations, resveratrol was unable to release cytochrome $\mathrm{c}$ to the cytosolic compartment in such a way (16). Therefore, whether capsaicin and resveratrol could induce cell death depends on the concentration exposed, the duration of exposure, the availability and efficiency of antioxidant capacity, as well as on the cell type.

Compared to capsaicin or resveratrol alone, a combination of the compounds was more effective in several significant antitumoric bioactivities, including $\mathrm{NO}^{\circ}$ production, DNA fragmentation and induction of apoptosis. Although this is not a synergistic effect, further studies are required to elucidate the mechanism of interaction between capsaicin and resveratrol for increased apoptotic potential. Our results suggest that tumor-associated $\mathrm{NO}^{\circ}$ is likely to be involved in the control of cancer. Thus, investigation of $\mathrm{NO}^{\circ}$-centered anticancer strategies is crucial; the source, output, chemistry and activity of $\mathrm{NO}^{\circ}$ in the tumor environment and the target cell type remain areas for further investigation.

In conclusion, we propose a mechanism for the capsaicin- and resveratrol-induced apoptotic pathway in human melanoma; the mitochondrial and death receptor pathways work together to induce apoptosis. These findings suggest that recognition of $\mathrm{NO}^{\bullet}$ as a target for apoptosis may provide a potential therapeutic strategy.

\section{Acknowledgements}

This study was supported by the Basic Science Research Program through the National Research Foundation of Korea (NRF) funded by the Ministry of Education, Science and Technology (no. 2011-0006617).

\section{References}

1. Megahed M, Schon M, Selimovic D and Schon MP: Reliability of diagnosis of melanoma in situ. Lancet 359: 1921-1922, 2002.

2. Soengas MS and Lowe SW: Apoptosis and melanoma chemoresistance. Oncogene 22: 3138-3151, 2003.

3. Jemal A, Siegel R, Ward E, et al: Cancer statistics, 2006. CA Cancer J Clin 56: 106-130, 2006.

4. Rezaul K, Wilson LL and Han DK: Direct tissue proteomics in human diseases: potential applications to melanoma research. Expert Rev Proteomics 5: 405-412, 2008. 
5. Garodia P, Ichikawa H, Malani N, Sethi G and Aggarwal BB: From ancient medicine to modern medicine: ayurvedic concepts of health and their role in inflammation and cancer. J Soc Integr Oncol 5: 25-37, 2007

6. Shimizu M and Weinstein IB: Modulation of signal transduction by tea catechins and related phytochemicals. Mutat Res 591: 147-160, 2005 .

7. Risberg T, Lund E, Wist E, Kaasa S and Wilsgaard T: Cancer patients use of nonproven therapy: a 5-year follow-up study. J Clin Oncol 16: 6-12, 1998.

8. Ferguson LR: Antimutagens as cancer chemopreventive agents in the diet. Mutat Res 307: 395-410, 1994.

9. Stavric B: Role of chemopreventers in human diet. Clin Biochem 27: 319-332, 1994

10. Cordell GA and Araujo OE: Capsaicin: identification, nomenclature, and pharmacotherapy. Ann Pharmacother 27: 330-336, 1993.

11. Surh YJ, Lee E and Lee JM: Chemoprotective properties of some pungent ingredients present in red pepper and ginger. Mutat Res 402: 259-267, 1998

12. Surh YJ and Lee SS: Capsaicin in hot chili pepper: carcinogen, co-carcinogen or anticarcinogen? Food Chem Toxicol 34: 313-316, 1996.

13. Li CQ and Wogan GN: Nitric oxide as a modulator of apoptosis Cancer Lett 226: 1-15, 2005.

14. Qiao S, Li W, Tsubouchi R, Murakami K and Yoshino M: Role of vanilloid receptors in the capsaicin-mediated induction of iNOS in PC12 cells. Neurochem Res 29: 687-693, 2004.

15. Qiao S, Li W, Tsubouchi R, Haneda M, Murakami K and Yoshino M: Involvement of peroxynitrite in capsaicin-induced apoptosis of C6 glioma cells. Neurosci Res 51: 175-183, 2005.

16. Pozo-Guisado E,MerinoJM,Mulero-Navarro S, et al: Resveratrolinduced apoptosis in MCF-7 human breast cancer cells involves a caspase-independent mechanism with down-regulation of Bcl-2 and NF-kappaB. Int J Cancer 115: 74-84, 2005.

17. Notas G, Nifli AP, Kampa M, Vercauteren J, Kouroumalis E and Castanas E: Resveratrol exerts its antiproliferative effect on HepG2 hepatocellular carcinoma cells, by inducing cell cycle arrest, and NOS activation. Biochim Biophys Acta 1760 1657-1666, 2006.

18. Ekmekcioglu S, Ellerhorst JA, Prieto VG, Johnson MM, Broemeling LD and Grimm EA: Tumor iNOS predicts poor survival for stage III melanoma patients. Int J Cancer 119: 861-866, 2006

19. Li CQ, Pang B, Kiziltepe T, et al: Threshold effects of nitric oxide-induced toxicity and cellular responses in wild-type and p53-null human lymphoblastoid cells. Chem Res Toxicol 19: 399-406, 2006

20. Liu L and Stamler JS: NO: an inhibitor of cell death. Cell Death Differ 6: 937-942, 1999

21. Olson SY and Garban HJ: Regulation of apoptosis-related genes by nitric oxide in cancer. Nitric Oxide: Jun 2, 2008 (E-pub ahead of print).

22. Shi Y, Lee JS and Galvin KM: Everything you have ever wanted to know about Yin Yang 1. Biochim Biophys Acta 1332: F49-F66, 1997.
23. Chen CW, Lee ST, Wu WT, Fu WM, Ho FM and Lin WW: Signal transduction for inhibition of inducible nitric oxide synthase and cyclooxygenase- 2 induction by capsaicin and related analogs in macrophages. Br J Pharmacol 140: 1077-1087, 2003.

24. Kim CS, Kawada T, Kim BS, et al: Capsaicin exhibits antiinflammatory property by inhibiting IkB-a degradation in LPS-stimulated peritoneal macrophages. Cell Signal 15: 299-306, 2003.

25. Oh GS, Pae HO, Seo WG, et al: Capsazepine, a vanilloid receptor antagonist, inhibits the expression of inducible nitric oxide synthase gene in lipopolysaccharide-stimulated RAW264.7 macrophages through the inactivation of nuclear transcription factor-kappa B. Int Immunopharmacol 1: 777-784, 2001.

26. Chan MM, Mattiacci JA, Hwang HS, Shah A and Fong D: Synergy between ethanol and grape polyphenols, quercetin, and resveratrol, in the inhibition of the inducible nitric oxide synthase pathway. Biochem Pharmacol 60: 1539-1548, 2000.

27. Kawada N, Seki S, Inoue M and Kuroki T: Effect of antioxidants, resveratrol, quercetin, and $\mathrm{N}$-acetylcysteine, on the functions of cultured rat hepatic stellate cells and Kupffer cells. Hepatology 27: 1265-1274, 1998.

28. Holian O, Wahid S, Atten MJ and Attar BM: Inhibition of gastric cancer cell proliferation by resveratrol: role of nitric oxide. Am J Physiol Gastrointest Liver Physiol 282: G809-G816, 2002.

29. Williams EL and Djamgoz MB: Nitric oxide and metastatic cell behaviour. Bioessays 27: 1228-1238, 2005.

30. Jung MY, Kang HJ and Moon A: Capsaicin-induced apoptosis in SK-Hep-1 hepatocarcinoma cells involves Bcl-2 down-regulation and caspase-3 activation. Cancer Lett 165: 139-145, 2001.

31. Mohan J, Gandhi AA, Bhavya BC, et al: Caspase-2 triggers Bax-Bak-dependent and -independent cell death in colon cancer cells treated with resveratrol. J Biol Chem 281: 17599-17611, 2006.

32. Dorrie J, Gerauer H, Wachter Y and Zunino SJ: Resveratrol induces extensive apoptosis by depolarizing mitochondrial membranes and activating caspase- 9 in acute lymphoblastic leukemia cells. Cancer Res 61: 4731-4739, 2001.

33. Tinhofer I, Bernhard D, Senfter M, et al: Resveratrol, a tumorsuppressive compound from grapes, induces apoptosis via a novel mitochondrial pathway controlled by Bcl-2. FASEB J 15 : 1613-1615, 2001

34. Delmas D, Rebe C, Lacour S, et al: Resveratrol-induced apoptosis is associated with Fas redistribution in the rafts and the formation of a death-inducing signaling complex in colon cancer cells. J Biol Chem 278: 41482-41490, 2003.

35. Mahyar-Roemer M, Kohler $\mathrm{H}$ and Roemer K: Role of Bax in resveratrol-induced apoptosis of colorectal carcinoma cells. BMC Cancer 2: 27, 2002.

36. Alonso M, Tamasdan C, Miller DC and Newcomb EW: Flavopiridol induces apoptosis in glioma cell lines independent of retinoblastoma and p53 tumor suppressor pathway alterations by a caspase-independent pathway. Mol Cancer Ther 2: 139-150, 2003. 